\title{
Thalassemia and its Management during Pregnancy
}

\author{
${ }^{1}$ Richa Saxena, ${ }^{2}$ Tania Banerjee, ${ }^{3}$ Rohit B Aniyery
}

\begin{abstract}
Thalassemia, also known as Mediterranean anemia, can be considered as the most common monogenetic disease prevailing all across the world. This disorder involves production of abnormal amounts of hemoglobin in the body, which poses a significant burden on the health and economic status of the patients as well as their families. Generally, patients with the thalassemia trait have a normal life expectancy, but individuals with beta thalassemia major mostly die from cardiac complications due to iron overload by the time they reach 30 years of age. Each year, nearly 70,000 babies are born with thalassemia worldwide. Conventional treatment procedures available (e.g., lifelong red blood cell transfusion, iron chelation therapy, and splenectomy) have levied high expenses on the health-care systems.

Thalassemia during pregnancy could be associated with significant complications to the mother as well as her fetus. Therefore, universal antenatal screening for thalassemia carriers should be implemented in populations having a high prevalence of this condition. In order to improve survival among children born with thalassemia, there is a requirement for combined treatment and prevention program during pregnancy. Preconception genetic counseling is strongly advised for all patients with thalassemia. Among the high-risk parents, the most important method for diagnosis of thalassemia is invasive prenatal diagnosis. Following a standard management plan and close monitoring of the maternal and fetal condition during pregnancy helps in considerably reducing the mortality and morbidity associated with this condition.

Novel treatment approaches are recently being developed to correct the resulting $\alpha / \beta$ globin chain imbalance, in an effort to move beyond the palliative management of this disease and tackle the exact genetic defect involved in its pathogenesis. Three methods for medical treatment of thalassemia have been envisioned: fetal globin gene renaissance by pharmacological compounds being injected into patients, allogeneic hematopoietic stem cell transplantation, and gene therapy. These medical strategies can be considered as the
\end{abstract}

\footnotetext{
${ }^{1}$ Head, ${ }^{2,3}$ Postgraduate

${ }^{1}$ Department of Obstetrics and Gynaecology, Jaypee Brothers Medical Publishers (P) Ltd., New Delhi, India

${ }^{2}$ Department of Biochemistry, University of Delhi, New Delhi, India

${ }^{3}$ Department of Applied Chemistry, Amity Institute of Applied Science, Amity University, Noida, Uttar Pradesh, India

Corresponding Author: Richa Saxena, Head, Department of Obstetrics and Gynaecology, Jaypee Brothers Medical Publishers (P) Ltd., New Delhi, India Phone: +919971234834 e-mail: synapse94@hotmail.com
}

best options prevailing now and are currently under research and clinical studies.

Keywords: $\alpha$-thalassemia, $\beta$-thalassemia, Allogeneic hematopoietic stem cell transplantation, Gene therapy, Iron chelation, Pregnancy management, Splenectomy, Thalassemia.

How to cite this article: Saxena R, Banerjee T, Aniyery RB. Thalassemia and its Management during Pregnancy. World J Anemia 2017;1(1):5-17.

\section{Source of support: Nil}

\section{Conflict of interest: None}

\section{INTRODUCTION}

Hemoglobinopathies encompass all genetic diseases of hemoglobin $(\mathrm{Hb})$ and are associated with an abnormality in one of the globin chains of $\mathrm{Hb}$ molecule. They fall into two major categories: quantitative defect (thalassemia syndromes; where production is affected) and qualitative defect (sickle cell syndrome where structure of the globin chain is abnormal). This review article puts light on the disease thalassemia, and its diagnosis and management during pregnancy.

The term thalassemia was coined by George Whipple and is derived from the Greek word "thalassa" for sea, and "hema" for blood. ${ }^{1}$ These can be defined as a group of inherited autosomal recessive hematologic disorders, which are caused due to a quantitative defect in the production of one or more $\mathrm{Hb}$ chains and are inherited in an autosomal recessive manner. ${ }^{2}$ The imbalance of globin chains causes excessive red blood cell (RBC) hemolysis and impairs bone marrow erythropoiesis. Based on the affected chain of the $\mathrm{Hb}$ molecule, thalassemia is divided further into $\alpha$ and $\beta$ thalassemia, described later.

\section{EPIDEMIOLOGY}

Thalassemias were initially distinctive in the tropics and subtropics but are now commonly found worldwide as a result of migration. Each year, more than 70,000 babies are born with thalassemia worldwide, ${ }^{3}$ and this defect is seen more often in the Indian subcontinent, the Mediterranean region, ${ }^{3}$ Southeast Asia, and West Africa. ${ }^{4}$ Most children with thalassemia are born to women in the lowincome countries. The World Health Organization recommends screening and genetic counseling for $\mathrm{Hb}$ disorders to be an intrinsic part of health-care system for improvement of survival among children born with thalassemia. ${ }^{5}$ 


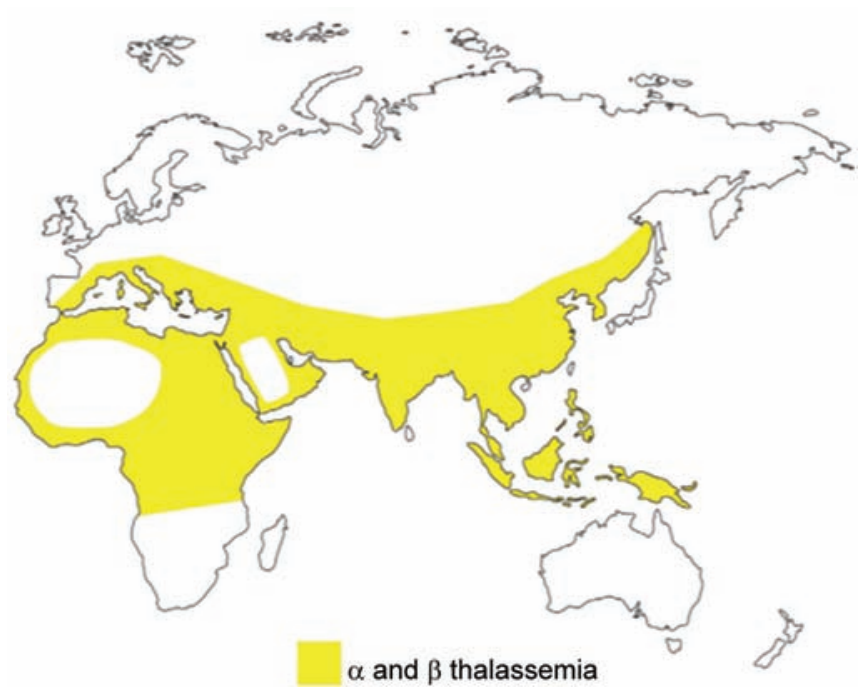

Fig. 1: The global distribution of $\alpha$ and $\beta$ thalassemias ${ }^{5}$

Approximately, 15 million people are globally affected by thalassemia. ${ }^{6}$ Both men and women are equally affected and this disorder occurs in approximately 4.4 of every 10,000 live births. Alpha thalassemia is more prevalent among individuals from African and Southeast Asian descent, whereas beta thalassemia is most common in persons of Mediterranean, African, and Southeast Asian descent (Fig. 1). 2,6

\section{PATHOPHYSIOLOGY}

To understand the nature of thalassemia syndrome, it is essential to get insight of the basic structure of $\mathrm{Hb}$ along with the interplay of the various polypeptide chains of $\mathrm{Hb}$ during normal human development.

\section{Intrauterine Development of Hemoglobin}

In the first trimester of intrauterine life, progression of $\mathrm{Hb}$ starts, where zeta, epsilon, alpha, and gamma chains achieve considerable levels. These chains rearrange in different forms to develop various types of embryonic $\mathrm{Hb}$ molecules. During intrauterine life, of all the different types of $\mathrm{Hb}$ molecules, only fetal $\mathrm{Hb}(\mathrm{HbF})$ endures and forms the principal respiratory pigment. The $\mathrm{HbF}$ consists of two $\alpha$ - and two $\gamma$-globin chains. Postpartum, after the age of 6 months, very low levels of $\mathrm{HbF}(<2 \%)$ are observed in the blood, ${ }^{7}$ due to the reduced production of $\gamma$-chains prior to birth. On the contrary, the concentration of $\beta$-chain progressively reaches from low level in early intrauterine life to a high proportion by the end of the third trimester and also persists into neonatal and adult life. All over the adult life, production of delta chains remains at a low level $(<3 \%)^{7}$

During the course of normal fetal development, all embryonic $\mathrm{Hbs}$ are superseded by the production of $\mathrm{HbF}$ (approximately 80\%), which gets further swapped by the adult $\mathrm{Hbs}, \mathrm{HbA}$ ( 2 alpha chains and 2 beta chains) and $\mathrm{HbA} 2$ ( 2 alpha chains and 2 delta chains). ${ }^{8}$ The developmental changes occurring in the production of human globin chain has been well illustrated in Graph 1 . Hence, by around 6 months of age, healthy infants will possess maximum amount of $\mathrm{HbA}$, very less amount of $\mathrm{HbA} 2$, and almost negligible $\mathrm{HbF}$.

\section{Structure of Adult Hemoglobin}

Hemoglobin is a tetramer molecule present in the RBCs, which consists of an iron-containing heme prosthetic group and four globin chains: Two $\alpha$ and two non- $\alpha$ (Fig. 2). ${ }^{8}$

The most bounteous human $\mathrm{Hb}, \mathrm{HbA}$, has two sets of globin chains, one set of $\alpha$ - and another $\beta$-globin chain. Four genes (two inherited from the mother and two from the father respectively) regulate the production of $\alpha$-globin chain, while only two genes (each inherited

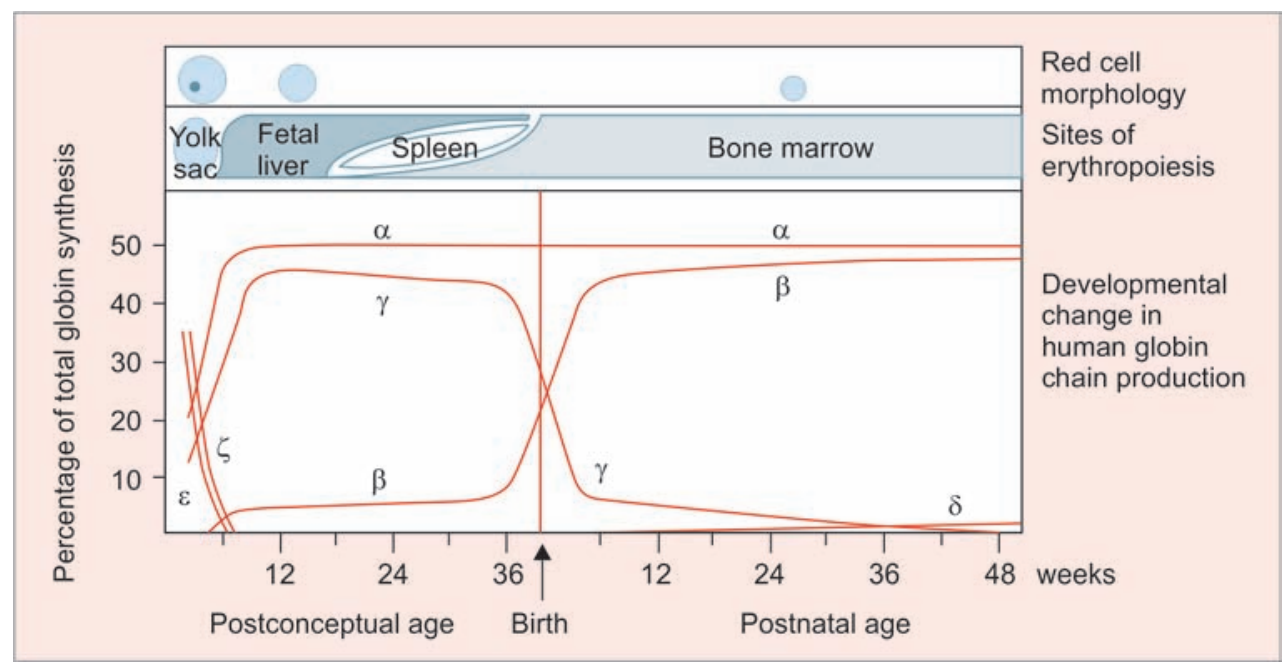

Graph 1: Developmental changes in human globin chain production, sites of erythropoiesis, and red cell morphology 


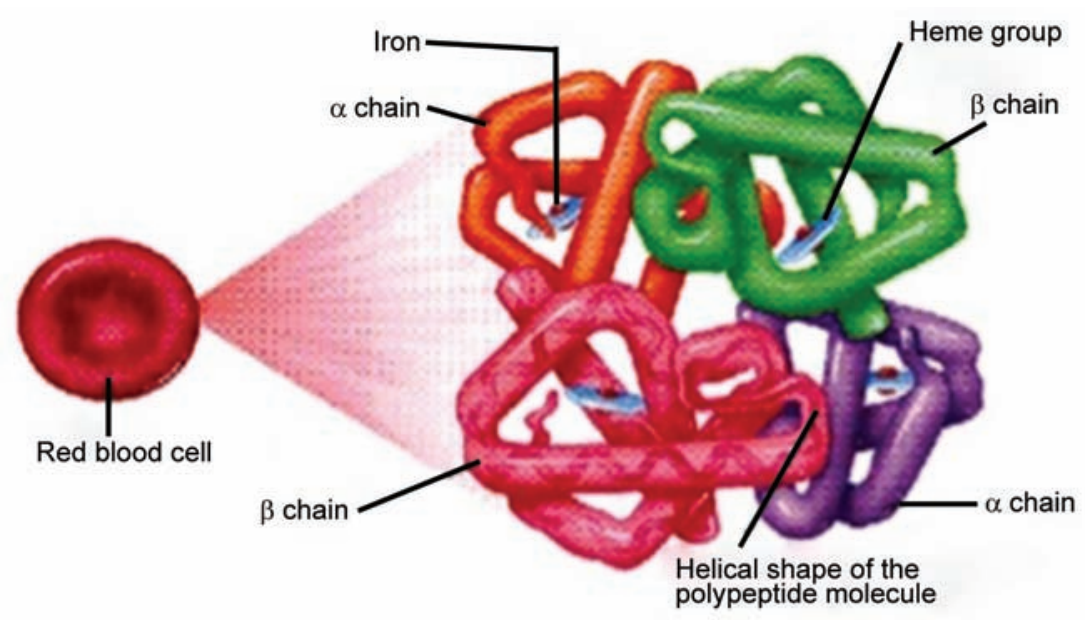

Fig. 2: Structure of adult hemoglobin

from father and mother) control the production of $\beta$-globin chain.

The thalassemia syndromes are characterized by a basic defect in the synthesis of one type of globin chains. As a result, there is insufficient $\mathrm{Hb}$ content in the resultant red cells. The other type of globin chains whose synthesis is not affected accumulates in the red cells, resulting in defective red cells, which are released into the circulation. Since damaged red cells are released into the peripheral circulation due to ineffective erythropoiesis, there occurs extravascular hemolysis. ${ }^{9-12}$

\section{Alpha-thalassemia}

The $\alpha$-globin gene, responsible for synthesis of $\alpha$-globin chain, resides on chromosome 16 and has four copies in each human diploid cell. ${ }^{7}$ Reduced production of $\alpha$-chain because of removal of at least one of the $\alpha$-globin chain loci gives rise to $\alpha$-thalassemia. ${ }^{13-15}$ Based on the number of genes affected (Table 1), $\alpha$-thalassemia has been classified into four types: (1) Hb Bart's hydrops; (2) $\mathrm{HbH}$ disease; (3) $\alpha$-thalassemia ${ }^{+}$trait; (4) silent carrier or $\alpha$-thalassemia minima (minor).

Deficiency in the synthesis of $\alpha$-globin chain influences $\mathrm{Hb}$ production in both fetal and adult life. This is because both $\mathrm{HbF}$ and $\mathrm{HbA}$ encompass $\alpha$-chains. Also, decreased production of $\alpha$-chains results in the following:

- Formation of $\gamma$-chain tetramers (Hb Bart's)

- Formation of $\beta$-chain tetramers $(\mathrm{HbH})$ and decreased production of $\mathrm{HbA} 2(\alpha 2 \delta 2)$ in adult life. ${ }^{16}$

\section{Beta-thalassemia}

The $\beta$-gene cluster region located on chromosome 11 regulates the synthesis of $\beta$-globin. $\beta$-thalassemia is the result of absent synthesis of $\beta$-globin chains. It occurs due to one or more than 200 point mutations. Rarely, it may also occur due to the deletion of two genes. Decreased production of $\beta$-globin chain leads to the excessive production of other chains, e.g., $\alpha$-globulin chains, $\gamma$-globulin chains,

Table 1: Various types of disorders, which can result depending upon the number of $\alpha$-globin genes affected

\begin{tabular}{ll}
\hline No. of affected genes & Type of $\alpha$-thalassemia disorder \\
\hline Four defective $\alpha$-globin genes ( $\left.\alpha^{0}\right)$ & $\begin{array}{l}\text { Hb Bart's hydrops (incompatible } \\
\text { with survival) }\end{array}$ \\
$\begin{array}{ll}\text { Three defective } \alpha \text {-globin genes } \\
\text { (two defective genes from one }\end{array}$ & $\begin{array}{l}\text { HbH disease (causing moderate } \\
\text { parent and one defective gene }\end{array}$ \\
from the other parent) ( $\left.\alpha^{0}+\alpha^{+}\right)$ & \\
Two defective $\alpha$-globin genes $\left(\alpha^{+}\right)$ & $\begin{array}{l}\alpha \text {-thalassemia } \\
\text { gene from each parent) }\end{array}$
\end{tabular}

$\alpha$-thalassemia ${ }^{0}$ trait (both defective genes from one parent)

One defective $\alpha$-globin genes $\left(\alpha^{+}\right) \quad \alpha$-thalassemia ${ }^{+}$trait or $\alpha$-thalassemia minima or $\alpha(+)$ thalassemia minor

Clinical features

This condition is incompatible with extrauterine life. Fetuses with this condition die either in utero or shortly after birth due to severe anemia

Such patients have severe anemia and a defect in the oxygen-carrying capacity. Erythroid hyperplasia can result in typical structural bone abnormalities with marrow hyperplasia, bone thinning, maxillary hyperplasia, and pathologic fractures

The affected individuals are clinically normal but frequently have minimal anemia and reduced $\mathrm{MCV}$ and $\mathrm{MCH}$. Red blood cell count is usually increased, typically exceeding $5.5 \times 10^{12} / \mathrm{L}$

The affected individuals exhibit no clinical abnormalities and may be hematologically normal or have mild reductions in $\mathrm{RBC}, \mathrm{MCV}$, and $\mathrm{MCH}$

MCV: Mean corpuscular volume; $\mathrm{MCH}$ : Mean corpuscular hemoglobin 
and $\delta$-globulin chains. ${ }^{12,13}$ Various forms of $\beta$-thalassemia has been illustrated in Table 2 .

\section{DIAGNOSIS}

\section{Clinical Presentation}

Newborns and children suffering from thalassemia minor have pallor, reduced growth, and abdominal distension.? Individuals with a carrier status are usually asymptomatic or may have mild or moderate symptoms related to anemia. This anemia may resemble iron deficiency anemia.

Patients with $\beta$-thalassemia major have a major illness. They may have severe anemia, which only responds to blood transfusion. Anemia begins to develop within the first 2 months after birth. It becomes progressively more severe. ${ }^{7,13}$

In all thalassemias, large numbers of imperfect red cells, containing excessive amounts of nonaffected globulin chains (e.g., alpha chains, gamma chains, and delta chains), are produced. These cells are destroyed in the bone marrow, giving rise to ineffective erythropoiesis, which is a prominent feature of the disease. ${ }^{17,18}$ This erythropoiesis causes skeletal deformities and bony fractures, megaloblastic anemia due to folate deficiency, and hyperuricemia with gout. Enlarged maxillary sinuses, a maxillary overbite, and "mongoloid" appearance of the face are commonly observed in thalassemic patients. These alterations can further assist to cause infections in the ears, nose, and throat. ${ }^{2,19-20}$ Symptoms associated with the various types of $\alpha$ - and $\beta$-thalassemia disorders are summarized in Tables 1 and 2, respectively.

\section{Investigations}

Many people who are salient carriers of the condition are likely to be completely unaware of the condition. Early diagnosis and prophylactic treatment is likely to cause a significant reduction in the disease-related mortality and morbidity. Some of the investigations which can be carried out in these cases include the following.

\section{Hematological Indices}

Screening for thalassemia is by examining the hematological indices (Table 3 ) and measurement of the $\mathrm{HbA} 2$ levels. Thalassemia traits are associated with a reduced mean corpuscular volume (MCV), reduced mean corpuscular hemoglobin $(\mathrm{MCH})$, and a normal to near-normal mean corpuscular hemoglobin concentration (MCHC). Of all these various markers, the most accurate marker is $\mathrm{MCH}^{18}$ Additionally, $\beta$-thalassemia is associated with elevated $\mathrm{HbA} 2$ levels (>3.5 gm\%). In $\alpha$-thalassemia trait, the changes may be minimal. Deoxyribonucleic acid (DNA) analysis may be required in these cases to confirm the diagnosis.

\section{Iron Profile Analysis}

Various parameters of the iron storage and usage by the body are measured by tests which include iron, ferritin,

Table 2: Various forms of $\beta$-thalassemia, depending upon the number of $\beta$-globin genes affected ${ }^{19}$

\begin{tabular}{lll}
\hline No. of affected genes & Type of beta thalassemia disorder & Clinical features \\
\hline $\begin{array}{l}\text { Inheritance of one defective } \beta \text {-globin gene from } \\
\text { each parent: Two genes are defective (severe } \\
\text { decrease in beta globin synthesis) }\left(\beta^{0}\right)\end{array}$ & $\begin{array}{l}\text { Beta thalassemia major or } \\
\text { Cooley anemia (homozygous } \\
\beta \text {-thalassemia) }\end{array}$ & $\begin{array}{l}\text { Synthesis of beta chains is almost completely } \\
\text { inhibited resulting in a severe transfusion- } \\
\text { dependent anemia at about } 3 \text { to } 6 \text { months of } \\
\text { age, the time when gamma-chain synthesis } \\
\text { normally decreases }\end{array}$ \\
\hline \multicolumn{2}{c}{ Beta thalassemia minor (One defective $\beta$-globin gene (from either parent) } \\
\hline $\begin{array}{l}\text { One defective } \beta \text {-globin genes from either parent } \\
\left(\beta^{+}\right) \text {(reduced synthesis of } \beta \text {-globin chains) }\end{array}$ & $\begin{array}{l}\text { Beta thalassemia trait/carrier state } \\
\text { (heterozygous state) }\end{array}$ & $\begin{array}{l}\text { Mild to moderate microcytic anemia with no } \\
\text { significant detrimental effect on overall health }\end{array}$ \\
$\begin{array}{l}\text { Heterogeneous group of thalassemia-like } \\
\text { disorders }\end{array}$ & Beta thalassemia intermedia & $\begin{array}{l}\text { Disease severity varies from the } \\
\text { asymptomatic carrier state to the severe } \\
\text { transfusion-dependent-type anemia }\end{array}$ \\
\hline
\end{tabular}

Table 3: Hematologic indices of iron deficiency and alpha and beta thalassemia ${ }^{18}$

\begin{tabular}{llll}
\hline Test & Iron deficiency & $\beta$-thalassemia & $\alpha$-thalassemia \\
\hline MCV (abnormal if $<80 \mathrm{fL}$ in adults; $<70 \mathrm{fL}$ in children & Low & Low & Low \\
6 months to 6 years of age; and $<76 \mathrm{fL}$ in children & & & \\
7 to 12 years of age) & High & Normal; occasionally high & Normal \\
RBC distribution width & Low & Normal & Normal \\
Ferritin & $>13$ & $<13$ & $<13$ \\
Mentzer index for children (MCV/RBC count) & Normal (may have & Increased HbA2, reduced HbA, & Adults: Normal \\
Hb electrophoresis & reduced HbA2) & and probably increased HbF & $*$ \\
& & &
\end{tabular}

*Newborns: May have $\mathrm{HbH}$ or $\mathrm{Hb}$ Bart's 
unsaturated iron binding capacity, total iron binding capacity, and percent saturation of transferrin. If an iron deficiency is the reason behind a person's anemia, it can be well determined by these tests. They can also aid in examining the degree of iron overload in thalassemic patients. $^{21}$

Due to the presence of microcytic RBCs, $\alpha$-thalassemia is at times confused with iron deficiency anemia. The amount of iron present in the blood of thalassemia individuals is not likely to be low. Prescribing iron supplements will be of no use to $\alpha$-thalassemic patients as it may lead to iron overload, which can gradually damage their organs with passage of time.

Indistinguishable $\beta$-thalassemia minor can also be well differentiated from iron deficiency or lead poisoning by using erythrocyte porphyrin tests. Normal porphyrin levels are observed in case of $\beta$-thalassemic patients, while elevated porphyrin levels have been noted in conditions where patients are suffering from iron deficiency anemia.

\section{Hemoglobin Evaluation/Electrophoresis}

Hemoglobin types and amount can be evaluated with the help of this test. The imbalance of $\alpha$ - and $\beta-\mathrm{Hb}$ chain formation in case of $\beta$-thalassemia leads to elevated levels of minor $\mathrm{Hb}$ components. Therefore, patients suffering from $\beta$-thalassemia major disorder generally have high percentage of $\mathrm{HbF}$, whereas an increased fraction of $\mathrm{HbA} 2$ levels is present in individuals having $\beta$-thalassemia minor. In certain cases of $\alpha$-thalassemia, $\mathrm{HbH}$ (a rare form of $\mathrm{Hb}$ ) may be observed.

\section{Peripheral Smear}

Peripheral smear in case of thalassemia is shown in Figure 3. Some of the characteristic features of thalassemic RBCs are polychromatic RBCs, microcytic RBCs,

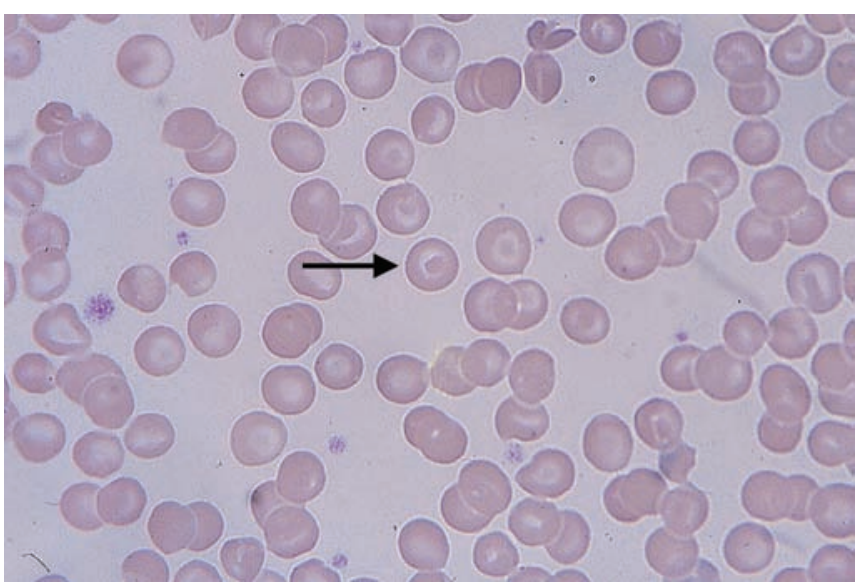

Fig. 3: Peripheral smear in case of thalassemia (target cell is indicated by an arrow)
RBCs differing in shape and size (poikilocytosis and anisocytosis), basophilic stippling (punctate basophilia), nucleated RBCs (normal, mature RBCs are enucleated), irregular distribution of $\mathrm{Hb}$ (resulting in "target cells" which appear like a bull's eye under the microscope).

\section{Deoxyribonucleic Acid Analysis}

Deoxyribonucleic acid analysis can be used to detect thalassemia and to determine silent carrier, if indicated. Mutations in the $\alpha$ - and $\beta$-globin genes are confirmed by using these tests. In $\alpha$-thalassemia, DNA analysis is used as a key molecular test for detecting mutations in the two alpha genes, HBA1 and HBA2, responsible for controlling the production of $\alpha$-globin chain. ${ }^{22-24}$

In case of $\beta$-thalassemia, analysis or sequencing of $\mathrm{Hb}$ $\beta$-gene, $H B B$, is done to check the presence of thalassemiacausing mutations. Greater than 250 mutations have been associated with $\beta$-thalassemia, though in some cases, it follows without any signs or symptoms. Presence of any of these mutations in the test will validate the diagnosis of $\beta$-thalassemia. ${ }^{23}$

\section{MANAGEMENT}

Women with thalassemia major and intermedia are at an increased risk of various maternal complications, such as cardiac failure, alloimmunization, viral infection, thrombosis, osteoporosis, new endocrinopathies, primarily, diabetes mellitus, hypothyroidism, and hypoparathyroidism due to the increasing iron burden, etc. ${ }^{24-27}$ In case of $\mathrm{Hb}$ Bart's hydrops, maternal complications may include early-onset severe preeclampsia in the antenal period; problems related to the delivery of a grossly hydropic fetus and placenta in the intrapartum period, and primary postpartum hemorrhage in the postpartum period. Also, the fetus may be at an increased risk of growth restriction and hydrops fetalis (due to $\mathrm{Hb}$ Bart's). Therefore, it is practical to follow a standard management plan and to closely monitor the maternal and fetal condition in this group of pregnant women. Various treatment options, such as blood transfusion or postpartum prophylaxis for thromboembolism may be indicated. However, since prevention is always better than cure, antenatal screening and an accurate genetic prenatal diagnosis should be preferably achieved during early gestation.

\section{Prevention}

\section{Genetic Counseling}

In countries with a high incidence of thalassemia, it is extremely important to offer prospective genetic counseling and to warn carriers about the risks of consanguineous marriage. However, till date, this approach has been 
relatively unsuccessful. Hence, considerable efforts have been directed toward prenatal diagnosis programs. In the developed countries, due to an increase in the immigrant population, screening for thalassemia becomes essential. In the UK, hemoglobinopathy screening should be offered without delay to the women with unknown hemoglobinopathy status having a normocytic or microcytic anemia in accordance with the National Health Service sickle cell and thalassemia screening program. ${ }^{28,29}$

\section{Prenatal Diagnosis}

Invasive prenatal diagnosis can be considered as the gold standard for establishing the diagnosis in high-risk couples. Since the carrier states of the thalassemias can be easily identified, affected fetuses can be diagnosed with the help of methods, such as preimplantation and preconception diagnosis. ${ }^{30}$ Recent efforts have been directed toward early diagnosis by fetal DNA analysis performed on fetal cells obtained via amniocentesis or chorionic villus sampling. ${ }^{31,32}$ Genetic testing of amniotic fluid may be sometimes used if the fetus is at increased risk for thalassemia. This is especially important if both the parents are likely to carry a mutation. These cases may be associated with an increased risk of their child inheriting a combination of abnormal genes, resulting in more severe form of thalassemia.

Also, the development of oligonucleotide probes to detect individual mutations has markedly increased the accuracy rate of prenatal diagnosis. An effort is being made for identifying the paternal mutation in the fetal cells from the maternal circulation for this purpose. ${ }^{33}$ Though presently in the experimental stage, this is likely to serve as an option for noninvasive prenatal diagnosis in the future.

Less invasive methods using ultrasound-based measurement of the cardiothoracic ratio can be done for prenatal diagnosis in cases of alpha thalassemia major.

\section{Management during Pregnancy}

\section{Periconceptional Care}

Screening and counseling prepregnancy: As previously described, screening should be done preconceptionally, especially in those individuals who are at an increased risk of being carriers for thalassemia and other hemoglobinopathies. Screening is able to identify couples having a $25 \%$ risk or more of having a pregnancy with a significant hemoglobinopathy. The most appropriate methods of screening for alpha and beta thalassemias include $\mathrm{MCH}(<27 \mathrm{pg})$ or MCV $(<80 \mathrm{fL})$. In case both these red cell indices are low, $\mathrm{Hb}$ pattern and iron profile are indicated.
If a pregnant woman is found to be carrier of a particular hemoglobinopathy, the partner needs to be screened as soon as possible. If there is a risk of the fetus having a major hemoglobinopathy, urgent expert counseling must be provided to the couple. This would enable them to make an informed choice regarding the prenatal diagnosis and the possible termination of pregnancy.

Medical treatment: Patients with thalassemia trait require no treatment or long-term monitoring. They usually do not have iron deficiency, so iron supplements are unlikely to improve their anemia. However, iron therapy needs to be administered if iron deficiency occurs. ${ }^{2,18}$ In the present times, the basis of treatment in cases of $\beta$-thalassemia major comprises of blood transfusion and iron chelation therapy. ${ }^{34}$

Iron chelation therapy: Body iron burden in the periconceptional period can be reduced and optimized with the help of aggressive iron chelation. This particularly helps in reducing the end-organ damage, especially diabetes and cardiomyopathy. ${ }^{5-9}$ Due to lack of safety data, all chelation therapy is possibly considered as teratogenic during the first trimester. Desferrioxamine (DFO) is the only chelating agent which can be used in the second and third trimesters. Iron chelators, such as deferasirox and deferiprone (DFP) must be ideally discontinued 3 months prior to conception and women must be converted to DFO iron chelation. Desferrioxamine, however, should be avoided in the first trimester as previously mentioned. It has been used safely during the second trimester after 20 weeks of gestation at low doses. ${ }^{34}$

Glycemic control and thyroid function tests: Diabetes is common among women with thalassemia. Women with diabetes should be preferably referred to a diabetologist. Good glycemic control is essential in the prepregnancy period. Women with established diabetes mellitus should preferably have serum fructosamine concentrations less than $300 \mathrm{nmol} / \mathrm{L}$ for at least 3 months prior to conception. This is equivalent to an $\mathrm{HbA} 1 \mathrm{c}$ of $43 \mathrm{mmol} / \mathrm{mol}^{35}$

Since hypothyroidism is frequently found in patients with thalassemia, thyroid function should be determined to ensure that the woman is in the euthyroid state prior to pregnancy. Untreated hypothyroidism causes not only an increased maternal morbidity, but also increased perinatal morbidity and mortality. ${ }^{36}$

Cardiovascular assessment: A cardiologist should preferably assess all women in the periconceptional period. An echocardiogram, electrocardiogram, and T2 star $\left(\mathrm{T} 2^{*}\right)$ cardiac magnetic resonance imaging (MRI) must be done. ${ }^{37}$

Liver iron concentration (LIC) assessment: Thalassemic women are more susceptible to develop cholelithiasis and cholecystitis, while liver cirrhosis due to iron overload or 
transfusion-related viral hepatitis may also be present. Liver iron concentration must be determined using a FerriScan ${ }^{\circledR}$. Ideally, the hepatic iron concentration should be less than $7 \mathrm{mg} / \mathrm{gm}$ [dry weight (dw)]. ${ }^{38,39}$ Ultrasound of liver and gall bladder (and spleen if present) should be performed. This helps in detecting cholelithiasis and evidence of liver cirrhosis due to iron overload or transfusion-related viral hepatitis.

Bone density scan: A number of factors could be responsible for causing osteoporosis among women with thalassemia. Some of these factors include underlying thalassemic bone disease, chelation of calcium by chelation drugs, hypogonadism, and vitamin D deficiency. Therefore, an effort must be made to assess the presence of preexisting osteoporosis by offering a bone density scan. The woman may be prescribed vitamin D supplements if required. ${ }^{40,41}$

Red cell antibodies: Approximately, $16.5 \%$ of individuals with thalassemia may have alloimmunity. Therefore, ABO and complete blood group genotype and antibody titers should be measured in women with thalassemia during the prepregnancy period. Presence of ABO or Rh red cell antibodies may be associated with an increased risk of hemolytic disease of the fetus and newborn. There also may be difficulty in obtaining suitable blood for transfusion if antibodies are present.

Immunization and antibiotic prophylaxis: Thalassemic women, who are HBsAg negative and may require blood transfusion, must be administered hepatitis B vaccination. Their hepatitis $\mathrm{C}$ status must also be established. Penicillin prophylaxis or its equivalent must be given to all women who have experienced splenectomy. Pneumococcus and Haemophilus influenzae type $b$ vaccination must also be administered to such women, especially if not done previously.

Folic acid supplementation: Beginning in the preconceptual period, at least 3 months prior to conception, folic acid must be administered to all pregnant women. Folic acid in the dosage of $5 \mathrm{mg} /$ day helps in preventing the neural tube defects.

\section{Antenatal Care}

Multidisciplinary team approach and antenatal assessment: As per the recommendations by the Royal College of Obstetricians and Gynaecologists, ${ }^{29}$ women with thalassemia should be reviewed on a monthly basis until 28 weeks of gestation and fortnightly thereafter. Women with thalassemia are best cared for in a multidisciplinary team setting, including an obstetrician with expertise in managing high-risk pregnancies and a hematologist. This team should provide prepregnancy counseling so that the woman is fully informed about the effect of thalassemia on pregnancy and vice versa. This team should also provide routine as well as specialist antenatal care. The initial antenatal assessment should include optimization of thalassemia management and screening for end-organ damage. The pattern of care should be individualized depending on the degree of end-organ damage.

Diabetic assessment: Such women must be frequently evaluated in the specialist diabetic pregnancy clinic and monthly assessment of serum fructosamine concentrations should also be done. ${ }^{35}$

Cardiac assessment: Specialist cardiac assessment must be performed in all women with thalassemia major at 28 weeks of gestation and thereafter as appropriate.

Thyroid function test: Thyroid function should be monitored regularly during pregnancy in hypothyroid patients.

Ultrasound scanning: Fertility treatment in the form of ovulation induction may be often required to achieve pregnancy in women with thalassemia. An early scan at 7 to 9 weeks of gestation is needed to determine viability as well as the presence of a multiple pregnancy. A detailed anomaly scan must also be done at 18 to $20^{+6}$ weeks of gestation. Serial fetal biometry scans must be offered at every 4-week interval from 24 weeks of gestation due to an increased risk of fetal growth restriction. ${ }^{29,42}$

Transfusion regimen: Blood transfusions must be offered regularly to all women with thalassemia major so as to attain pretransfusion $\mathrm{Hb}$ levels of 100 to $120 \mathrm{gm} / \mathrm{L}$. Initially, a 2 to 3 unit transfusion should be administered. Additional top-up transfusion may be given the following week if needed. The $\mathrm{Hb}$ levels should be monitored at every 2- to 3-week intervals. If at any stage the $\mathrm{Hb}$ levels fall below $100 \mathrm{gm} / \mathrm{L}$, a 2-unit blood transfusion may be given.

Oral iron therapy: Serum ferritin levels must be checked in all women with hemoglobinopathy. If their ferritin level is less than $30 \mathrm{mg} / \mathrm{L}$, oral iron supplements may be offered. Parenteral iron must never be prescribed in these cases.

Folic acid supplementation: Individuals with thalassemia must be prescribed folic acid in the dosage of $5 \mathrm{mg} /$ day. $^{43}$

\section{Intrapartum Care}

Thalassemia in itself is not an indication for cesarean section. Cesarean delivery is not required in the absence of an obstetric indication. Cross-matched blood should preferably be arranged prior to delivery, especially in the presence of alloimmunity. Also, in women with thalassemia major, intravenous (IV) DFO in the dosage of $2 \mathrm{gm}$ over 24 hours should be administered for the duration of 
labor. ${ }^{44}$ Continuous intrapartum electronic fetal monitoring should be started.

\section{Postpartum Care}

Women with thalassemia are at high risk for venous thromboembolism due to the presence of abnormal red cells in the circulation. Prophylaxis with low-molecularweight heparin should be administered during the postpartum period in such women. ${ }^{2,34}$ Additionally, lowmolecular-weight heparin should be administered for a week post-discharge following vaginal delivery or for 6 weeks following cesarean section. ${ }^{31}$

Breastfeeding is safe and should be encouraged. In women with thalassemia major, DFO should be restarted in the postpartum period as soon as the 24-hour infusion of IV DFO, which had been started during the intrapartum period, is completed. Though DFO is secreted in breast milk, it is not orally absorbed and therefore, not harmful to the newborn. Presently, there is minimal safety data regarding the use of other iron chelators at the time of breastfeeding.
In addition, there is no contraindication to the use of hormonal methods of contraception, such as the combined oral contraceptive pill, the progestogen-only pill, hormonal implants, and the Mirena ${ }^{\circledR}$ intrauterine system in women with thalassemia. ${ }^{45}$

\section{Medical Management}

The main treatment options, which may be used in medical management, are outlined below in details and are summarized in Figure 4:

- Blood transfusions

- Chelation therapy - removal of excess iron overload in body

- Stem cell or bone marrow transplants (BMT)

- $\Upsilon$-globin induction

- Gene therapy

\section{Blood Transfusions}

In order to maintain $\mathrm{Hb}$ at a level higher than $9.5 \mathrm{gm} /$ $\mathrm{dL}$, the patient with beta thalassemia needs lifelong periodic blood transfusion. ${ }^{2,46}$ The blood transfusion
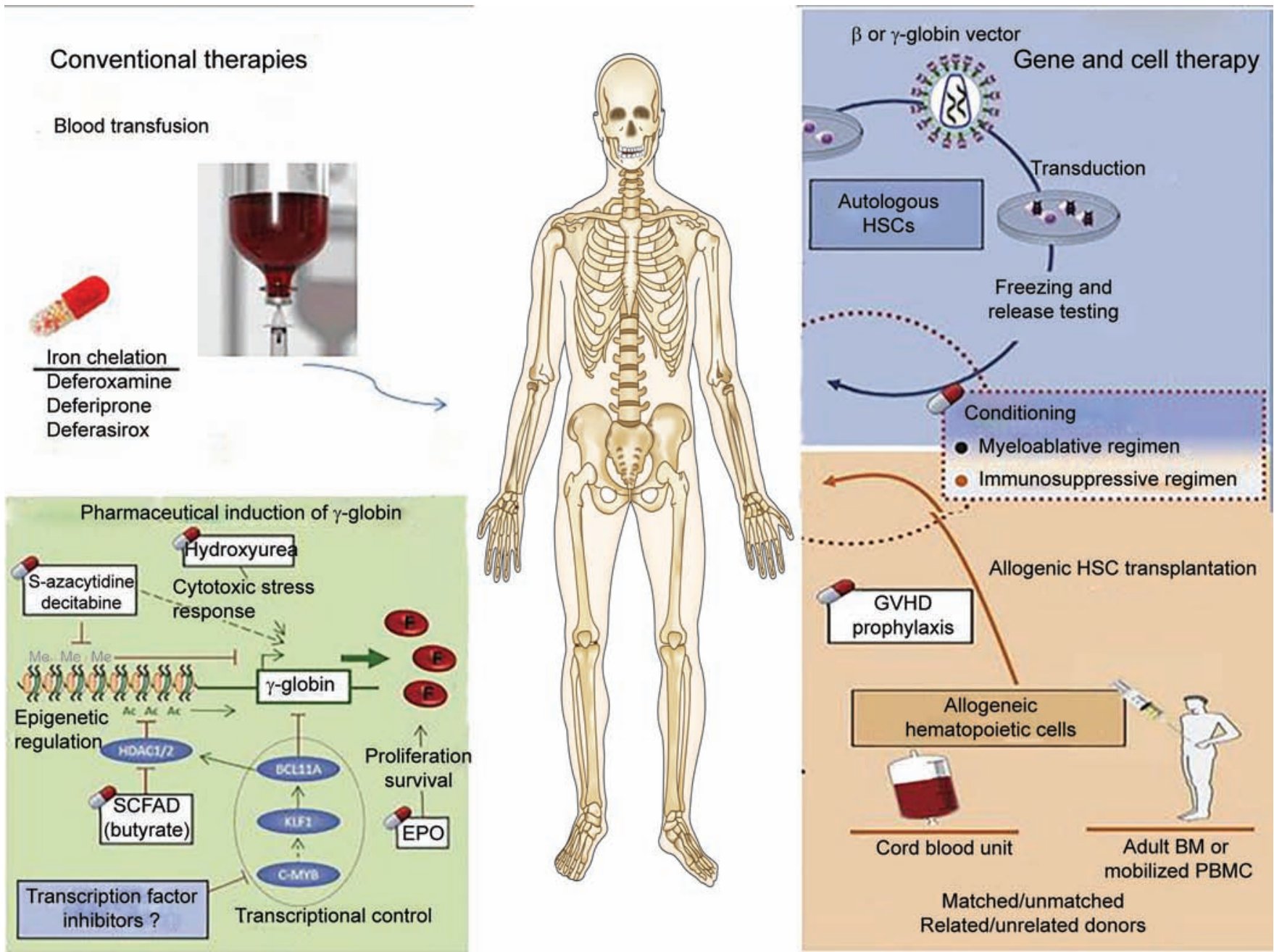

Fig. 4: Schematic diagram showing therapies for beta thalassemia. EPO: Erythropoietin; HSC: Hematopoietic stem cells; GVHD: Graft versus host disease; BM: Bone marrow; PBMC: Peripheral blood mononuclear cell; SCFAD: Small chain fatty acid derivative 
process is generally initiated as early as 6 months of age. Transfusion requirements are occasional and become obligatory when the person's $\mathrm{Hb}$ is inadequate for a normal life or when the anemia damages growth and development.

Complications of blood transfusion: Though blood transfusions can be considered as one of the safest option, repeated transfusions lead to iron overload in multiple organs and tissues of the patient, resulting in life-threatening problems, such as endocrine dysfunction, cardiomyopathy, liver disease, transfusional hemosiderosis, etc. Complications like extramedullary hematopoiesis and massive erythroid hyperplasia commonly occur in inadequately transfused patients due to the body's effort for compensating the RBC loss, ultimately resulting in premature death. Patients with beta thalassemia major die within the first 5 years of life due to the lack of transfusion. Merely 50 to $65 \%$ of patients live beyond the age of 35 years even after having transfusions, that too in developed or high-income countries. ${ }^{47-49}$ In order to overcome these complications, medications for removing excessive iron overload become an important requirement.

\section{Chelation Therapy}

Each unit of transfused RBCs contains approximately 200 mg of elemental iron. Moreover, anemia and ineffective erythropoiesis downregulate the synthesis of hepcidin, a protein that acts as the vital regulator for iron entry into the blood circulation. ${ }^{50,51}$

Chelation therapy is a treatment process for eliminating excessive iron overload in the body as a result of multiple blood transfusions. Due to the lack of physiological process for removing excessive iron from the body due to multiple transfusions, transfusion-dependent patients require treatment with an iron chelator between 5 and 8 years of age. ${ }^{52}$ Generally, chelation therapy is started at an age of 2 to 4 years after 20 to 25 RBC units have been transfused, serum ferritin levels are more than $1000 \mu \mathrm{g} / \mathrm{dL}$, and LIC estimated by liver biopsy or by noninvasive hepatic $\mathrm{T}_{2} \mathrm{MRI}$ is more than $3 \mathrm{mg}$ iron/gm dw. ${ }^{53}$

Various chelating agents, which are currently available, are as follows (Table 4):

- Desferrioxamine: Desferrioxamine is currently approved in the United States and this agent is administered via slow continuous subcutaneous infusion using a portable pump for 8 to 12 hours, generally five or six times a week. It can also be administered via IV and intramuscular routes. Desferrioxamine is readily soluble in water and approximately $8 \mathrm{mg}$ of iron is bound by $100 \mathrm{mg}$ of DFO. It is excreted through bile and urine that results in red discoloration of urine. It easily chelates iron from ferritin and hemosiderin, but fails to chelate iron from transferrin. ${ }^{12,13}$

- Deferiprone/Ferriprox: An oral chelation agent (approved in Europe and the United States in October 2011) is generally advised based on the decrease in serum ferritin levels. It is prescribed to the transfusion-dependent patients, when the current chelation therapy proves to be insufficient. However, no major controlled trials have been conducted to evaluate its direct treatment advantages, like improvement in disease-related symptoms. Normally, it is available in the market as 500-mg, film-coated tablets. ${ }^{12,13}$

- Deferasirox (Exjade): The US Food and Drug Administration (FDA) approved this drug in the year 2005. It is one of the selective trivalent iron chelators which decreases the LIC and serum ferritin levels. ${ }^{54,55}$ It is available in the market as an oral suspension or tablet $^{31}$ which reduces LIC and serum ferritin levels in the patients. This chelating agent has more affinity for iron and binds with it in a ratio of $2: 1$. It has been approved for use in multiple blood transfusiondependent and nontransfusion-dependent thalassemia patients. ${ }^{56,57}$

- Deferoxamine (Desferal): This drug can be administered subcutaneously or intravenously. Though it is comparatively a nontoxic therapy, its administration can be both tedious and expensive. Adverse effects of deferasirox include transient gastrointestinal problems. So far no cases of agranulocytosis have been reported. ${ }^{58}$

Table 4: Medications currently used for chelation therapy ${ }^{59}$

\begin{tabular}{llll}
\hline & & & $\begin{array}{l}\text { Controlled } \\
\text { substances } \\
\text { Drug name }\end{array}$ \\
Hydroxyurea (off-label) & $\mathrm{Rx}$ & $\mathrm{D}$ & $\mathrm{N}$ \\
Deferasirox & $\mathrm{Rx}$ & $\mathrm{C}$ & $\mathrm{N}$ \\
Deferiprone & $\mathrm{Rx}$ & $\mathrm{D}$ & $\mathrm{N}$ \\
Exjade & $\mathrm{Rx}$ & $\mathrm{C}$ & $\mathrm{N}$ \\
Ferriprox & $\mathrm{Rx}$ & $\mathrm{D}$ & $\mathrm{N}$ \\
Jadenu & $\mathrm{Rx}$ & $\mathrm{C}$ & $\mathrm{N}$
\end{tabular}

Off-label, The drug has not been approved for a particular use by the FDA; Rx, Medical prescription; OTC, Over the counter; Rx/ OTC, Prescription or over the counter; C, Animal studies show contrary effect on the fetus, and there are no well-controlled clinical trials in humans. However, possible benefits may permit its use in pregnant women despite its adverse risks; D, Positive indication of human fetal risk based on contrary reaction data from clinical trials in humans, but probable benefits may permit its use in pregnant women in spite of its adverse risks; N, Not subjected to the Controlled Substances Act

\section{Gamma-globulin Inducers}

Pharmacological induction of the fetal $\gamma$ globin gene and the resultant formation of $\mathrm{HbF}\left(\alpha_{2} / \gamma_{2}\right)$ in adult erythroid 
cells act as a reasonable therapeutic strategy for severe $\beta$-thalassemias. Large number of drugs have been tested, including cytotoxic compounds and epigenetic regulators. The demethylating agent 5-azacitidine is the first drug which was found to increase $\gamma$-globin expression. Small-chain fatty acid derivatives (SCFAD) (e.g., arginine butyrate) inhibit histone deacetylation, thereby increasing $\gamma$-globin expression. The only currently approved drug for $\gamma$-globin induction is hydroxyurea. It acts through multiple mechanisms. Its cytotoxic activity is thought to accelerate the differentiation process and to stimulate cellular stress response pathways, leading to an overall increase in the number of F cells. Gamma-globin gene induction by other cytotoxic agents may also be mediated by this stress response.

Numerous nonselective compounds, like erythropoietin (EPO), cytotoxic compounds, and SCFAD, have also been assessed in clinical trials. ${ }^{60}$ Erythropoietin has proliferative and antiapoptotic properties. They are thought to act through epigenetic mechanisms since a durable association exists between epigenetic change and the developmental shape of globin gene expression. ${ }^{61-63}$ The combined administration of recombinant EPO together with cytotoxic drugs has also been found to be beneficial for patients with low baseline EPO levels.

\section{Bone Marrow Transplant}

Correction of this hematopoietic disorder using BMT was first demonstrated by Thomas et $\mathrm{al}^{64}$ in a young patient with $\beta$-thalassemia major who had not undergone transfusions. Allogeneic BMT in childhood is one of the curative therapies for beta thalassemia major. ${ }^{65}$ Study by Lucarelli et al $^{66}$ has demonstrated that bone marrow transfusion for patients under the age of 16 years is associated with a high probability of complication free survival, particularly in the absence of hepatosplenomegaly or portal fibrosis.

Hematopoietic stem cell transplantation (HSCT) involves transplantation of multipotent hematopoietic cells usually derived from bone marrow, peripheral blood, or umbilical cord blood. This process normally produces outstanding result in low-risk persons having regular chelation therapy. Recognized protocols using HSCT can help achieve thalassemia-free survival. Therefore, several centers have utilized HSCT method as a conclusive therapy. ${ }^{67}$ Many factors have been shown to affect patient outcome following BMT as follows: severity criteria before transplantation (hepatomegaly, portal fibrosis, and irregular chelation history), age at transplantation, source of stem cells (e.g., peripheral blood, bone marrow, cord blood), histocompatibility (related matched, unrelated matched, mismatched, haploidentical), preparative conditioning regimen, and pretransplant eradication of marrow hyperplasia. ${ }^{56,68-70}$ Still, chronic graft-versus-host disease is a major long-term complication of allogeneic HSCT. As a result, use of BMT as a treatment modality presently remains inadequate. However, in the near future, the group of potential donors may broaden with the progress of new techniques to advance the management of graft-versus-host disease, e.g., performing BMT from unrelated donors and cord blood stem cells.

\section{Gene Therapy}

Gene therapy holds the capability of "fixing" the patient's bone marrow cells by transferring the normal $\beta$-globin or $\gamma$-globin gene into hematopoietic stem cells (HSCs), which helps in permanently producing normal RBCs. Most important requirement for effective gene transfer in cases of $\beta$-thalassemia is regulated, erythroid-specific, consistent, and high-level $\beta$-globin or $\gamma$-globin expression. Retroviral vector-mediated gene transfer into HSCs provides a potentially curative therapy for severe $\beta$-thalassemia. However, they may be associated with the following defects: (i) limited capacity, (ii) instability, and (iii) an inability to transduce nondividing cells (most HSCs are quiescent). ${ }^{71}$ These drawbacks have prevented the efficient correction of beta thalassemia by the infusion of genetically modified HSCs.

Lentiviral vectors based on human immunodeficiency virus have been recently developed for this purpose and have been shown to be effective for curing thalassemia in mouse models. One participant in an ongoing clinical trial has achieved independence from transfusion after gene transfer into bone marrow stem cells mediated via lentivirus. ${ }^{72}$ Ongoing efforts need to be focused on improving the efficiency of lentiviral vector-mediated gene transfer into stem cells so that the curative potential of gene transfer can be consistently achieved.

\section{CONCLUSION}

Inherited autosomal recessive disorder like thalassemia is a major global health concern. The currently available literature indicates that optimization of body iron reserves in cases of thalassemia is likely to reduce the end-organ damage, thereby decreasing the incidence of endocrinopathies or cardiac problems. Pregnancy was previously rare in cases of transfusion-dependent $\beta$-thalassemia major. However, nowadays with the aggressive use of iron chelation therapy, the rate of pregnancy in women with thalassemia major is fast increasing. Proper management of pregnant thalassemia patient by appropriate fetal and maternal monitoring during the periconceptional, antenatal, intrapartum, and postpartum periods can 
considerably help reduce the associated maternal and neonatal mortality and morbidity. Novel medical management procedures like fetal globin gene renaissance by pharmacological compounds being injected into patients, allogeneic HSCT, and gene therapy are currently emerging as gold standards. However, these treatment options are currently under research stages and long-term efficacy and safety studies are underway.

\section{REFERENCES}

1. Whipple GH, Bradford WL. Mediterranean disease: thalassemia (erythroblastic anemia of Cooley). J Pediatr 1936 Sep;9(3):279-311.

2. Rund D, Rachmilewitz E. Beta-thalassemia. N Engl J Med 2005 Sep 15;353(11):1135-1146.

3. Fawdry AL. Erythroblastic anaemia of childhood (Cooley's anaemia) in Cyprus. Lancet 1944;1:171-176.

4. Weatherall DJ. The thalassemias. In: Beutler B, Lichtman MA, Coller BS, Kipps TJ, Seligsohn S, editors. Williams hematology. 6th ed. New York: McGraw-Hill; 2001. p. 562-564.

5. Thalassaemia and Other Haemoglobinopathies [accessed Mar 2017]. Agenda Item 5.2. 59th World Health Assembly, 2006 May 27. EB118.R1. Available from: http://www.who. int/gb/ebwha/pdf_files/EBSS-EB118-2006-REC1/english/ Res/res-eb118_2006_rec1-en.pdf.

6. Global Distribution of Thalassemia [online] [Accessed 2017 Mar]. Available from: www.iawesome12.blogspot. in/2012/03/global-distribution-of-thalassemia.html.

7. Marengo-Rowe AJ. The thalassemias and related disorders. Proc (Bayl Univ Med Cent) 2007 Jan;20(1):27-31.

8. Hemoglobin and Myoglobin - The Medical Biochemistry [online] [Accessed 2017 Mar]. Available from: www.themedicalbiochemistrypage.org/hemoglobin-myoglobin.php.

9. Marengo-Rowe AJ. Haemoglobinopathies. Br J Hosp Med 1971;6:617-630.

10. Wood WG. Increased $\mathrm{HbF}$ in adult life. Baillieres Clin Haematol 1993 Mar;6(1):177-213.

11. Clegg JB, Weatherall DJ, Na-Nakorn S, Wasi P. Haemoglobin synthesis in beta-thalassaemia. Nature 1968 Nov 16;220(5168):664-668.

12. Schroeder WA, Huisman TH, Shelton JR, Shelton JB, Kleihauer EF, Dozy AM, Robberson B. Evidence for multiple structural genes for the gamma chain of human fetal hemoglobin. Proc Natl Acad Sci USA 1968 Jun;60(2):537-544.

13. Muncie HL, Campbell JS. Alpha and beta thalassemia. Am Fam Physician 2009 Aug 15;80(4):339-344.

14. Nathan DG, Lodish HF, Kan YW, Housman D. Beta thalassemia and translation of globin messenger RNA. Proc Natl Acad Sci USA 1971 Oct;68(10):2514-2518.

15. Shinar E, Rachmilewitz EA. Oxidative denaturation of red blood cells in thalassaemia. Semin Hematol 1990 Jan;27(1): 70-82.

16. Weatherall DG, Clegg JB. The thalassemia syndromes. 4th ed. Oxford (UK): Blackwell; 2000.

17. Pootrakul P, Sirankapracha P, Hemsorach S, Moungsub W, Kumbunlue R, Piangitjagum A, Wasi P, Ma L, Schrier SL. A correlation of erythrokinetics, ineffective erythropoiesis, and erythroid precursor apoptosis in Thai patients with thalassemia. Blood 2000 Oct 1;96(7):2606-2612.
18. Olivieri NF. The beta-thalassemias [published correction appears in N Engl J Med 1999;341(18):1407]. N Engl J Med 1999;341(2):99-109.

19. Cunningham MJ, Macklin EA, Neufeld EJ, Cohen AR, Thalassemia Clinical Research Network. Complications of beta-thalassemia major in North America. Blood 2004 Jul 1; 104(1):34-39.

20. Ryan K, Bain BJ, Worthington D, James J, Plews D, Mason A, Roper D, Rees DC, de la Salle B, Streetly A, et al. Significant haemoglobinopathies: guidelines for screening and diagnosis. Br J Haematol 2010 Apr;149(1):35-49.

21. Thalassemia. Centers for Disease Control and Prevention [Accessed 2017 Mar]. Available from: http:/ / www.cdc.gov / ncbddd/thalassemia/index.html.

22. Fucharoen S, Winichagoon P, Thonglairoam V, Siriboon W, Siritanaratkul N, Kanokpongsakdi S, Vantanasiri C. Prenatal diagnosis of thalassemia and hemoglobinopathies in Thailand: experience from 100 pregnancies. Southeast Asian J Trop Med Public Health 1991 Mar;22(1):16-29.

23. Sirichotiyakul S, Saetung R, Sanguansermsri T. Prenatal diagnosis of beta-thalassemia/Hb E by hemoglobin typing compared to DNA analysis. Hemoglobin 2009;33(1):17-23.

24. Cao A, Galanello R. Beta-thalassemia. Genet Med 2010 Feb;12(2):61-76.

25. Eldor A, Rachmilewitz EA. The hypercoagulable state in thalassemia. Blood 2002 Jan 1;99(1):36-43.

26. Cappellini MD, Robbiolo L, Bottasso BM, Coppola R, Fiorelli G, Mannucci AP. Venous thromboembolism and hypercoagulability in splenectomized patients with thalassaemia intermedia. Br J Haematol 2000 Nov;111(2):467-473.

27. Jensen CE, Tuck SM, Agnew JE, Koneru S, Morris RW, Yardumian A, Prescott E, Hoffbrand AV, Wonke B. High prevalence of low bone mass in thalassaemia major. Br J Haematol 1998 Dec;103(4):911-915.

28. Modell B, Khan M, Darlison M. Survival in beta-thalassaemia major in the UK: data from the UK Thalassaemia Register. Lancet 2000 Jun 10;355(9220):2051-2052.

29. Royal College of Obstetricians and Gynaecologists. Management of beta thalassaemia in pregnancy green-top guideline no. 66. London: RCOG; 2014.

30. Cao A, Kan YW. The prevention of thalassemia. Cold Spring Harb Perspect Med 2013 Feb 1;3(2):a011775.

31. Pennell D, Porter JB, Cappellini MD, Li CK, Aydinok Y, Lee CL, Kattamis A, Smith G, Habr D, Domokos G, et al. Efficacy and safety of deferasirox $\left(\right.$ Exjade $^{\circledR}$ ) in reducing cardiac iron in patients with $\beta$-thalassaemia major: results from the cardiac substudy of the EPIC trial [abstract]. Blood 2008;112:3873.

32. Leung TN, Lau TK, Chung TKh. Thalassaemia screening in pregnancy. Curr Opin Obstet Gynecol 2005 Apr;17(2):129-134.

33. Cao A, Rosatelli MC. Screening and prenatal diagnosis of the haemoglobinopathies. Baillieres Clin Haematol 1993 Mar;6(1):263-286.

34. Weatherall DJ. Thalassaemia in the next millennium. Keynote address. Ann N Y Acad Sci 1998 Jun 30;850:1-9.

35. Spencer DH, Grossman BJ, Scott MG. Red cell transfusion decreases hemoglobin A1c in patients with diabetes. Clin Chem 2011 Feb;57(2):344-346.

36. De Groot L, Abalovich M, Alexander EK, Amino N, Barbour L, Cobin RH, Eastman CJ, Lazarus JH, Luton D, Mandel SJ, et al. Management of thyroid dysfunction during pregnancy and postpartum: an Endocrine Society clinical practice guideline. J Clin Endocrinol Metab 2012 Aug;97(8):2543-2565. 
37. Lupton M, Oteng-Ntim E, Ayida G, Steer PJ. Cardiac disease in pregnancy. Curr Opin Obstet Gynecol 2002 Apr;14(2): 137-143.

38. Borgna-Pignatti C, Rugolotto S, De Stefano P, Zhao H, Cappellini MD, Del Vecchio GC, Romeo MA, Forni GL, Gamberini MR, Ghilardi R, et al. Survival and complications in patients with thalassemia major treated with transfusion and deferoxamine. Haematologica 2004 Oct;89(10):1187-1193.

39. Olivieri NF, Brittenham GM. Iron-chelating therapy and the treatment of thalassemia. Blood 1997 Feb 1;89(3):739-761.

40. Jensen CE, Tuck SM, Agnew JE, Koneru S, Morris RW, Yardumian A, Prescott E, Hoffbrand AV, Wonke B. High incidence of osteoporosis in thalassaemia major. J Pediatr Endocrinol Metab 1998;11 (Suppl 3):975-977.

41. WalshJM,McGowanCA,KilbaneM,McKennaMJ,McAuliffeFM. The relationship between maternal and fetal vitamin $\mathrm{D}$, insulin resistance, and fetal growth. Reprod Sci 2013 May;20(5):536-541.

42. Origa R, Piga A, Quarta G, Forni GL, Longo F, Melpignano A, Galanello R. Pregnancy and $\beta$-thalassemia: an Italian multicenter experience. Haematologica 2010 Mar;95(3): 376-381.

43. Prevention of neural tube defects: results of the Medical Research Council Vitamin Study. Lancet 1991 Jul 20;338(8760): 131-137.

44. Orr D. Difficult intubation: a hazard in thalassaemia - a case report. Br J Anaesth 1967 Jul;39(7):585-586.

45. Neinstein Ls Katz B. Patients with hematologic disorders need careful birth control counseling. Contracept Technol Update 1985 Mar;6(3):43-46

46. Cazzola M, Borgna-Pignatti C, Locatelli F, Ponchio L, Beguin Y, De Stefano P. A moderate transfusion regimen may reduce iron loading in beta-thalassemia major without producing excessive expansion of erythropoiesis. Transfusion.1997 Feb;37(2):135-140.

47. Borgna-Pignatti $C$. The life of patients with thalassemia major. Haematologica 2010 Mar;95(3):345-348.

48. Modell B, Khan M, Darlison M, Westwood MA, Ingram D, Pennell DJ. Improved survival of thalassaemia major in the $\mathrm{UK}$ and relation to $\mathrm{T} 2 *$ cardiovascular magnetic resonance. J Cardiovasc Magn Reson 2008 Sep 25;10:42.

49. Thuret I, Pondarre C, Loundou A, Steschenko D, Girot R, Bachir D, Rose C, Barlogis V, Donadieu J, de Montalembert M, et al. Complications and treatment of patients with betathalassemia in France: results of the National Registry. Haematologica 2010 May;95(5):724-729.

50. Ganz T. Hepcidin and iron regulation, 10 years later. Blood 2011 Apr 28;117(17):4425-4433.

51. Liu J, Sun B, Yin H, Liu S. Hepcidin: a promising therapeutic target for iron disorders. Medicine (Baltimore) 2016 Apr;95(14):e3150.

52. Roberts DJ, Brunskill SJ, Doree C, Williams S, Howard J, Hyde CJ. Oral deferiprone for iron chelation in people with thalassaemia. Cochrane Database Syst Rev 2007 Jul 18;(3):CD004839.

53. Rachmeitewitz EA, Giardina PJ. How I treat thalassemia. Blood 2011 Sep 29;118(13):3479-3488.

54. Oliveri NF, Brittenham GM, McLaren CE, Templeton DM, Cameron RG, McClelland RA, Burt AD, Fleming KA. Longterm safety and effectiveness of iron-chelation therapy with deferiprone for thalassemia major. N Engl J Med 1998 Aug 13;339(7):417-423.
55. Angeliucci E, Barosi G, Camaschella C, Cappellini MD, Cazzola M, Galanello R, Marchetti M, Piga A, Tura S. Italian Society of Hematology practice guidelines for the management of iron overload in thalassemia major and related disorders. Haemtologica 2008 May;93(5):741-752.

56. Taher AT, Porter JB, Kattamis A, Viprakasit V, Cappellini MD. Efficacy and safety of iron-chelation therapy with deferoxamine, deferiprone, and deferasirox for the treatment of iron-loaded patients with nontransfusion-dependent thalassemia syndromes. Drug Des Devel Ther 2016 Dec 15;10: 4073-4078.

57. Angelucci E, Santini V, Di Tucci AA, Quaresmini G, Finelli C, Volpe A, Quarta G, Rivellini F, Sanpaolo G, Cilloni D, et al. Deferasirox for transfusion-dependent patients with myelodysplastic syndromes: safety, efficacy, and beyond (GIMEMA MDS0306 trial). Eur J Haematol 2014 Jun;92(6):527-536.

58. Besa EC, Advani P. Beta thalassemia medication [online] [Accessed 2017 Mar]; 2016. Available from: www.emedicine. medscape.com/article/206490-medication.

59. Medications for Thalassemia [online] [Accessed 2017 Mar]. Available from: https:/ / www.drugs.com/condition/thalassemia.html.

60. Perrine SP. Fetal globin induction - can it cure beta thalassemia? Hematol Am Soc Hematol Educ Program 2005: 38-44.

61. Kiefer CM, Hou C, Little JA, Dean A. Epigenetics of betaglobin gene regulation. Mutat Res 2008 Dec 1;647(1-2): 68-76.

62. Mabaera R, Richardson CA, Johnson K, Hsu M, Fiering S, Lowrey $\mathrm{CH}$. Developmental- and differentiation-specific patterns of human gamma- and beta-globin promoter DNA methylation. Blood 2007 Aug 15;110(4):1343-1352.

63. Yin W, Barkess G, Fang X, Xiang P, Cao H, Stamatoyannopoulos G, Li Q. Histone acetylation at the human beta-globin locus changes with developmental age. Blood 2007 Dec 1;110(12):4101-4107.

64. Thomas ED, Buckner CD, Sanders JE, Papayannopoulou T, Borgna-Pignatti C, De Stefano P, Sullivan KM, Clift RA, Storb R. Marrow transplantation for thalassaemia. Lancet $1982 \mathrm{Jul}$ 31;2(8292):227-229.

65. Carey BW, MarkoulakiS, Hanna J,Saha K, Gao Q, Mitalipova M, Jaenisch R. Reprogramming of murine and human somatic cells using a single polycistronic vector. Proc Natl Acad Sci USA 2009 Jan 6;106(1):157-162.

66. Lucarelli G, Galimberti M, Polchi P, Angelucci E, Baronciani D, Giardini C, Politi P, Durazzi SM, Muretto P, Albertini F. Bone marrow transplantation in patients with thalassemia. N Engl J Med 1990 Feb 15;322(7):417-421.

67. Chin JY, Kuan JY, Lonkar PS, Krause DS, Seidman MM, Peterson KR, Nielsen PE, Kole R, Glazer PM. Correction of a splice-site mutation in the beta-globin gene stimulated by triplex-forming peptide nucleic acids. Proc Natl Acad Sci USA 2008 Sep 9;105(36):13514-13519.

68. Lucarelli G, Clift RA, Galimberti M, Polchi P, Angelucci E, Baronciani D, Giardini C, Andreani M, Manna M, Nesci S, et al. Marrow transplantation for patients with thalassemia: results in class 3 patients. Blood 1996 Mar 1;87(5): 2082-2088.

69. Giardini C, Galimberti M, Lucarelli G. Bone marrow transplantation in thalassemia. Annu Rev Med 1995;46:319-330.

70. Lucarelli G, Galimberti M, Polchi P, Angelucci E, Baronciani D, Durazzi SM, Giardini C, Agostinelli F, Donati M, Giorgi C, 
et al. A new approach to bone marrow transplantation in thalassemia. Ann N Y Acad Sci 1990;612:394-397.

71. Sadelain M, Wang CH, Antoniou M, Grosveld F, Mulligan RC. Generation of a high-titer retroviral vector capable of expressing high levels of the human beta-globin gene. Proc Natl Acad Sci USA 1995 Jul 18;92(15):6728-6732.
72. Wilber A, Hargrove PW, Kim YS, Riberdy JM, Sankaran VG, Papanikolaou E, Georgomanoli M, Anagnou NP, Orkin SH, Nienhuis AW, et al. Therapeutic levels of fetal hemoglobin in erythroid progeny of $\beta$-thalassemic CD34+ cells after lentiviral vector-mediated gene transfer. Blood 2011 Mar 10;117(10):2817-2826. 